\title{
Metabolic syndrome in clinical practice
}

We read with interest Fisman and Tenenbaum review [1] that discuss the predictive value of the metabolic syndrome (MetS) in terms of cardiovascular (CV) morbidity and mortality, thus highlighting its importance as an additional tool to estimate individual $\mathrm{CV}$ risk. A few comments may be of interest.

Apart from non-alcoholic fatty liver disease (NAFLD) and hyperuricemia [2] already mentioned in the review, MetS has also been linked to chronic kidney disease (CKD) [3] and peripheral artery disease (PAD) [4]. We have previously shown that MetS patients without diabetes had similar vascular disease prevalence (including coronary heart disease, stroke and PAD as those with diabetes but without MetS (24.1\% vs. $25.4 \%$, respectively) [5].

Statins play an important role in the treatment of MetS [6]. We have previously reported that statins, either alone (in the GREek Atorvastatin and Coronary heart disease Evaluation [GREACE] Study) or as a part of a multifactorial intervention (in Assessing The Treatment Effect in Metabolic syndrome without Perceptible diabeTes [ATTEMPT] study), may improve not only CV risk but also serum uric levels, kidney and renal function [7-10]; these beneficial effects were more prominent in CKD and NAFLD patients. Therefore, clinicians should keep in mind that these disease states related to MetS might help to intensify and tailor treatment to maximize clinical benefit.

Conflict of interest: This letter was written independently; no company or institution supported the authors financially or by providing a professional writer. N.K. has given talks and attended conferences sponsored by Novartis, Pfizer, MSD and AstraZeneca. A.K. has given talks and attended conferences sponsored by Menarini, AstraZeneca, Novartis and Pfizer. V.G.A. has nothing to declare.

\section{References}

1. Fisman EZ, Tenenbaum A. The metabolic syndrome entanglement: Cutting the Gordian knot. Cardiol J, 2014; 21: 1-5.

2. Katsiki N, Athyros VG, Karagiannis A, Mikhailidis DP. Characteristics other than the diagnostic criteria associated with metabolic syndrome: An overview. Curr Vasc Pharmacol, 2013 Apr 25. [Epub ahead of print].

3. Gluba A, Mikhailidis DP, Lip GY, Hannam S, Rysz J, Banach M. Metabolic syndrome and renal disease. Int J Cardiol, 2013; 164: 141-150.

4. Garg PK, Biggs ML, Carnethon M et al. Metabolic syndrome and risk of incident peripheral artery disease: The cardiovascular health study. Hypertension, 2014; 63: 413-419.

5. Athyros VG, Mikhailidis DP, Papageorgiou AA et al.; METS-GREECE Collaborative Group. Prevalence of atherosclerotic vascular disease among subjects with the metabolic syndrome with or without diabetes mellitus: the METS-GREECE Multicentre Study. Curr Med Res Opin, 2004; 20: 1691-1701.

6. Katsiki N, Athyros VG, Karagiannis A, Mikhailidis DP. The role of statins in the treatment of type 2 diabetes mellitus: An update. Curr Pharm Des, 2013 Sep 12. [Epub ahead of print].

7. Athyros VG, Mikhailidis DP, Liberopoulos EN et al. Effect of statin treatment on renal function and serum uric acid levels and their relation to vascular events in patients with coronary heart disease and metabolic syndrome: A subgroup analysis of the GREek Atorvastatin and Coronary heart disease Evaluation (GREACE) Study. Nephrol Dial Transplant, 2007; 22: 118-127.

8. Athyros VG, Karagiannis A, Ganotakis ES et al.; Assessing The Treatment Effect in Metabolic syndrome without Perceptible diabeTes (ATTEMPT) Collaborative Group. Association between the changes in renal function and serum uric acid levels during multifactorial intervention and clinical outcome in patients with metabolic syndrome. A post hoc analysis of the ATTEMPT study. Curr Med Res Opin, 2011; 27: 1659-1668.

9. Athyros VG, Giouleme O, Ganotakis ES et al. Safety and impact on cardiovascular events of long-term multifactorial treatment in patients with metabolic syndrome and abnormal liver function tests: a post hoc analysis of the randomised ATTEMPT study. Arch Med Sci, 2011; 7: 796-805.

10. Athyros VG, Tziomalos K, Gossios TD et al.; GREACE Study Collaborative Group. Safety and efficacy of long-term statin treatment for cardiovascular events in patients with coronary heart disease and abnormal liver tests in the Greek Atorvastatin and Coronary Heart Disease Evaluation (GREACE) Study: A post-hoc analysis. Lancet, 2010; 376: 1916-1922.

Niki Katsiki, Vasilios G. Athyros, Asterios Karagiannis

$2^{\text {nd }}$ Department of Internal Medicine, Medical School, Aristotle University of Thessaloniki, Hippocration Hospital, 15 Marmara St, Thessaloniki, Greece, tel: 00302310 892606, fax: 00302310445220 , e-mail:athyros@med.auth.grorvathyros@gmail.com 